\title{
Increased Gene Expression by Cationic Liposomes (TFL-3) in Lung Metastases Following Intravenous Injection
}

\author{
Wenhao LI, ${ }^{a}$ Tatsuhiro IshidA, ${ }^{a}$ Yurie OKADA, ${ }^{a}$ Naoto OKU, ${ }^{b}$ and Hiroshi KiwadA ${ }^{*, a}$ \\ ${ }^{a}$ Department of Pharmacokinetics and Biopharmaceutics, Faculty of Pharmaceutical Sciences, The University of \\ Tokushima; 1-78-1 Sho-machi, Tokushima 770-8505, Japan: and ${ }^{b}$ Department of Medical Biochemistry and COE \\ program in the 21st Century, University of Shizuoka School of Pharmaceutical Sciences; 52-1 Yada, Shizuoka 422-8526, \\ Japan. Received November 22, 2004; accepted January 13, 2005
}

We recently showed that size, not surface charge, is a major determinant of the in vitro lipofection efficiency of pDNA/TFL-3 complex (lipoplex), even in the presence of serum. In this study, the effect of lipoplex size as a result of interaction with serum proteins on in vitro lipofection and the relationship of this with in vivo lipofection was examined in a murine lung metastasis model. As previously described, the pDNA to lipid ratio (P/L ratio) affected both the size and zeta potential of the lipoplex. In vitro studies also indicated that transgene expression in B16BL6 cells was largely dependent on the size of the lipoplex, both in the absence or presence $(50 \%(\mathrm{v} / \mathrm{v})) \mathrm{of}$ serum. An in vivo lipofection experiment showed that predominant gene expression in lungs occurred only in tumor-bearing mice, not in normal mice. Based on the in vitro study, this tumor-related gene expression was not related to lipoplex size in the presence of serum $(50 \%(\mathrm{v} / \mathrm{v}))$, suggesting that the size alteration, as the result of interactions with serum proteins in the blood stream may not play an important role in the case of systemic injections. In addition, the efficient gene expression in tumor-bearing lung was not related to the progression of lung metastases. The area-specific gene expression in tumor-bearing lungs, which was largely dependent on the $\mathrm{P} / \mathrm{L}$ ratio of the lipoplexes, was observed by fluorescent microscopy. Although the underlying mechanism for the area-specific transgene expression is not clear, it may be related to the interaction of lipoplexes with tumor cells, vascular endothelial cells under angiogenesis and normal cells in the lungs. The possibility that TFL-3 is a useful utility to the targeted delivery of pDNA to lungs and tumor-related lipofection is demonstrated. This result suggests that area-specific gene expression in lung metastases may be achieved by controlling the physicochemical properties of the lipoplex, i.e. the $\mathrm{P} / \mathrm{L}$ ratio.

Key words gene delivery; lipofection; lung metastasis; cationic liposome

Gene therapy, a promising medical technology against many diseases, has some potential for the treatment of certain types of serious cancer such as lung cancer. ${ }^{1)}$ During the past 15 years, more than 400 clinical studies in gene therapy have been evaluated and almost $70 \%$ of these studies were in the area of cancer gene therapy. ${ }^{2,3)}$ However, even though much clinical research has been carried, the validity of this treatment has not been confirmed. ${ }^{4)}$

The key for successful gene therapy in the treatment of cancer is the technology used for gene delivery, in which targeted gene delivery to a tumor is achieved. For this purpose, many studies have been directed toward the development of a useful vector system. Vectors for gene therapy can be categorized into two groups: viral and non-viral vectors. The viral vectors mimic the properties of viruses that naturally infect cells and transfer their genetic materials, resulting in a highly efficient gene transfer. They have, however, some limitations which include difficulty for production and toxicity (in particular immunogenecity). ${ }^{5}$ Non-viral vectors based on (poly)cationic lipids, liposomes, and polymers form negatively charged natural and synthetic DNA. It is generally believed that the positive charge on the vector/DNA complex ensures its binding to the cell membrane because of the negative charge on the cell membrane and it then enters the target cells. Although the gene transfer efficiency of non-viral vectors is less than that of their viral counterparts and is also transient in nature, these systems are likely to present several advantages including low-cost and large-scale production, safety, lower immunogenecity, and the capacity to deliver large gene fragments.

A cationic liposome, TFL-3, composed of a cationic lipid,
DC-6-14, with helper lipids dioleoylphosphatidylethanolamine (DOPE) and cholesterol (CHOL), showed a higher lipofection efficiency in dividing or non-dividing cells in vitro, even in the presence of serum ${ }^{6-8)}$ and in vivo. ${ }^{9)}$ Generally, gene fragments in complexes formed with non-viral vectors are easily and quickly degraded in the presence of serum. ${ }^{10)}$ An electron microscopic study showed that gene fragments/TFL-3 complexes (lipoplexes) retained their morphology in the presence of serum. ${ }^{6}$ This may account for the high gene transfer activity in serum-containing media and in vivo. Based on the above discussion, TFL-3 would be expected to be a superior non-viral vector that could be systemically injected.

In vivo lipofection, the transgene expression would occur as a function of the distribution of the lipoplexes. In addition to the physicochemical properties of the component lipids, the colloidal properties of lipoplexes such as their stability in plasma, pharmacokinetics and biodistribution are major determinant factors achieving the highest transgene and tissue specific expressions. ${ }^{11-14)}$ Organ distribution can be modulated by varying the lipid-to-pDNA ratio or the size of the lipoplexes. ${ }^{15)}$

With the aging of society in the 21 st century, the incidence of cancer is expected to increase. The morbidity rate of lung cancer has been rising particularly rapidly, and a pressing countermeasure is necessary. ${ }^{16)}$ Lipoplexes usually accumulate largely in the lung, although the distribution changes with time: lipoplexes are found in the lung shortly after intravenous injection but eventually accumulate in the liver after 24 or $48 \mathrm{~h}^{17{ }^{178)}}$ This is because the lipoplex form aggregates in the blood stream, and is captured in the first capillary en- 
countered. If the pDNA could be quickly transferred from lipoplexes to pulmonary endothelial cells after being captured in a capillary of the lung, an enhanced transgene expression might be obtained. In a lung with a tumor, a more extensive gene expression would be observed because of the angiogenesis of vessels and the proliferation of cells in the tumor area.

The focus of this study, therefore, was on the in vitro characterization of lipoplexes (pDNA/TFL-3 complex) and the relationship between their characteristics and in vitro or in vivo transgene expression. For this purpose, we employed a line of highly lung-metastatic melanoma cells, B16BL6, to study in vitro transgene expression efficiency and a murine lung metastatis model to examine in vivo efficiency.

\section{MATERIALS AND METHODS}

Materials TFL-3 composed of $O, O^{\prime}$-ditetradecanoyl- $N$ ( $\alpha$-trimethylammonioacetyl) diethanolamine chloride/DOPE/ CHOL $(1 / 0.75 / 0.75, \mathrm{~mol} / \mathrm{mol})$ was a generous gift from the Daiichi Pharmaceutical Co. Ltd. (Tokyo, Japan). The luciferase assay kit and cell culture lysis reagent (CCLR) were purchased from Promega (WI, U.S.A.). Plasmid DNA (pDNA) pCAG-Luc3 encoding the firefly luciferase, was purchased from Nippon Gene (Toyama, Japan). A pDNA encoding the green fluorescence protein (GFP) gene, gWIZ-GFP was obtained from Gene Therapy Systems, Inc (CA, U.S.A.). pDNA was amplified in E. Coli JM 109 and purified by means of a QIAfilter Plasmid Mega Kit from Qiagen (Hilden, Germeny). LipofectAMINE was purchased from Invitrogen (CA, U.S.A.). Fetal bovine serum (FBS) was purchased from GIBCO BRL (NY, U.S.A.). Opti-MEM I medium was purchased from Life Technologies (MD, U.S.A.). Other cell culture regents were obtained from Nissui Pharmaceutical Co. Ltd. (Tokyo, Japan). All other reagents were of analytical grade.

Cell Line and Animal B16BL6, a murine melanoma cell line, was cultured in DMEM medium supplemented with $10 \%$ heat-inactivated FBS, $10 \mathrm{~mm}$ glutamine, 100 units $/ \mathrm{ml}$ penicillin, and $100 \mu \mathrm{g} / \mathrm{ml}$ streptomycin in a $5 \% \mathrm{CO}_{2}$ air incubator at $37^{\circ} \mathrm{C}$. Six-week-old male C57BL6 mice, $20-22 \mathrm{~g}$ in weight, were purchased from Japan SLC (Shizuoka, Japan). They had free access to water and rat chow, and were housed under controlled environmental conditions (constant temperature, humidity, and a $12 \mathrm{~h}$ dark-light cycle). All animal experiments were evaluated and approved by the Animal and Ethics Review Committee of Faculty of Pharmaceutical Sciences, The University of Tokushima.

Preparation of pDNA/TFL-3 Complex (Lipoplex) Lipoplex was prepared by gently mixing the appropriate amount of pDNA into TFL-3 with different lipid concentrations $(2.5 \mu \mathrm{M}$ or $25 \mu \mathrm{M})$ to obtain the desired pDNA to lipid ratio. The $\mathrm{pDNA}$ to lipid $(\mathrm{P} / \mathrm{L})$ ratio was varied from 0 to $150 \mathrm{~g}$ pDNA per total lipid (mol) in liposomes, corresponding to a mol ratio of $0-2.8 \times 10^{-5}$. The lower lipid concentration was for in vitro use and the higher concentration was for in vivo use.

Characterization of the Lipoplex The particle size and zeta-potential of the resulting lipoplex in $9 \%$ sucrose solution with or without $50 \%(\mathrm{v} / \mathrm{v})$ serum were determined using a laser particle analyzer and a laser electrophoresis zeta poten- tial analyzer device, NICOMP 380 (Particle sizing system, CA, U.S.A.).

In Vitro Transfection B16BL6 cells were plated in 12well plates at a density of $1.5 \times 10^{5}$ cells/well. After an over night pre-culture, the first $200 \mu \mathrm{l}$ of Opti MEM or serum was added to a well of a 12-well plate, then $200 \mu$ l of lipoplex $(2.5 \mu \mathrm{g} \mathrm{pDNA} / \mathrm{ml})$ was immediately added. After $1 \mathrm{~h}$ of lipofection, the lipoplex was removed and the wells were washed twice with cold phosphate buffered saline (PBS, $\mathrm{pH} 7.4$ ). Appropriate medium supplemented with 10\% heat-inactivated FBS was then added and the cells were cultured for a further $23 \mathrm{~h}$. For the luciferase assay, after removal of the medium, the cells were lysed by the addition of $400 \mu \mathrm{l}$ of CCLR. The cell lysate was collected and centrifuged ( $2 \mathrm{~min}$, $20000 \times \boldsymbol{g}, 4^{\circ} \mathrm{C}$ ) to give a clear supernatant for the assay. The luciferase assay was carried out according to the manufacturer's recommended protocol (Promega, WI, U.S.A.). The protein content in the clear supernatant was determined with a DC protein assay kit (Bio-Rad Laboratories, CA, U.S.A.). The data are expressed as light counts $/ \mathrm{min} / \mathrm{mg}$ of protein.

In Vivo Transfection To induce pulmonary metastases, murine B16BL6 melanoma cells $\left(5 \times 10^{4}\right.$ cells/mouse $)$ were intravenously injected with $0.2 \mathrm{ml}$ of $\mathrm{PBS}(-)$ via the tail vein of a C57BL/6 mouse. At the indicated day after the inoculation, lipoplex was intravenously injected via the tail vein. The dose of pDNA for injection was fixed at $30 \mu \mathrm{g}$. At $24 \mathrm{~h}$ after the injection, the lungs were removed from the mouse. To dissect, the lung was homogenized followed by three freeze-thaw cycles in $1 \mathrm{ml}$ of CCLR. The resulting tissue homogenate was then centrifuged $\left(10 \mathrm{~min}, 20000 \times \boldsymbol{g}, 4^{\circ} \mathrm{C}\right)$. The clear supernatant was subjected to the luciferase assay as described above.

Fluorescent Microscopic Study Lipoplex containing pDNA encoding the green fluorescence protein (GFP) gene, gWIZ-GFP (30 $\mu \mathrm{g} \mathrm{pDNA} / \mathrm{mouse})$, was intravenously injected into a B16BL6-bearing mouse via the tail vein. At $24 \mathrm{~h}$ after in vivo lipofection, the lungs were removed from the mice, immediately embedded in 4\% CMC embedding compound (FINETEC Co., Ltd., Tokyo, Japan), frozen in liquid nitrogen, and stored at $-80^{\circ} \mathrm{C}$. Frozen lung sections $(100 \mu \mathrm{m}$ thick) were made using a cryostat by the routine procedure. The sections were directly examined using a Zeiss LSM5 inverted confocal laser scan microscope (Carl Zeiss, Germany) without any fixation. GFP was imaged using $488 \mathrm{~nm}$ for excitation and $510-530 \mathrm{~nm}$ for emission.

Statistics All mean values are expressed as the mean \pm S.D. Statistical analyses were performed using GraphPad InStat software (GraphPad Software, CA, U.S.A.). The level of significance was set at $p<0.05$.

\section{RESULTS}

Effect of P/L Ratio on Size, Zeta Potential and Transfection Efficiency of the Lipoplex The size of the lipoplex was examined for varying ratios of pDNA to lipid of TFL-3 liposomes $(\mathrm{P} / \mathrm{L}$ ratio) in the absence of serum (Fig. 1A). The mean size of the original TFL-3 before preparation of the lipoplex was approximately $150 \mathrm{~nm}$. Complexing of liposomes with an increasing amount of pDNA, up to $80 \mathrm{P} / \mathrm{L}$ ratio, resulted in a dramatic increase in the size of lipoplex. At a $\mathrm{P} / \mathrm{L}$ ratio of 80 , the largest size lipoplex was obtained. 

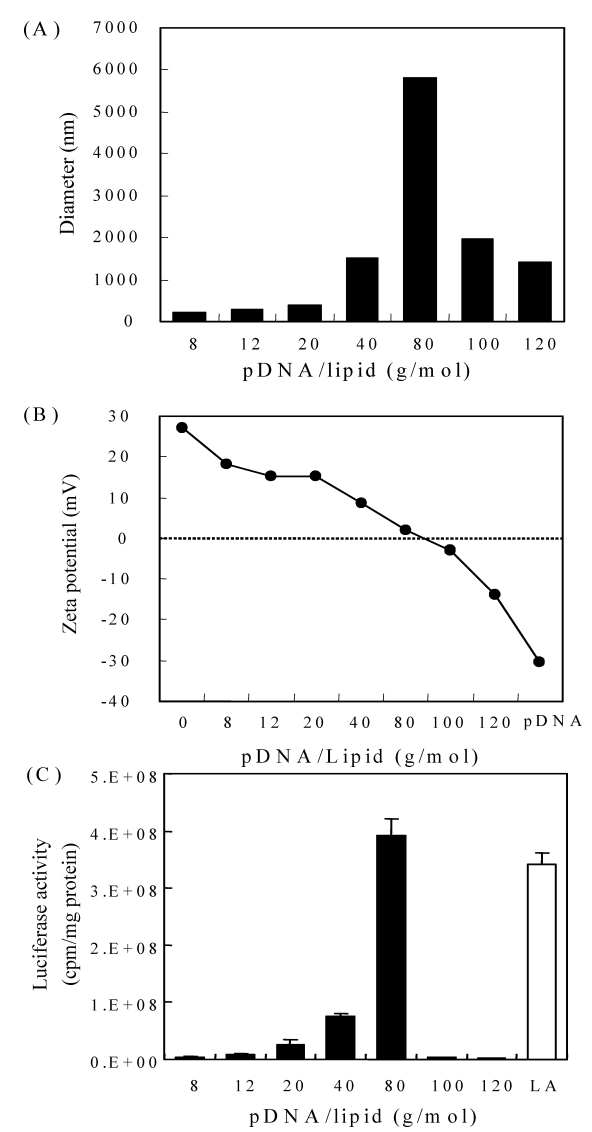

Fig. 1. Effect of P/L Ratio on Size, Zeta Potential and Transfection Efficiency of the Lipoplex

pDNA/TFL-3 complexes (lipoplexes) were prepared, as described method in Materials and Methods. The average size (A) and zeta-potential (B) of the resulting lipoplex were determined. Luciferase activity (C) in B16BL6 cells following lipofection (1 $\mu \mathrm{g}$ of pDNA) was determined, as described in Materials and Methods. Filled column, pDNA/TFL-3 complex; open column, pDNA/LipofecAMINE (LA) complex. Data represent mean \pm S.D. $(n=3)$.

This can be attributed to extensive, uncontrolled aggregation and fusion between lipoplexes due to their loss of surface charge. Conversely, the complexing of greater amounts of pDNA with liposomes resulted in a decrease in size.

Complexing of an increasing amount of pDNA with cationic liposomes led to a decrease in the initial zeta potential value of the liposome (approximately $+28 \mathrm{mV}$ ) (Fig. 1B). Lipoplex with a $80 \mathrm{P} / \mathrm{L}$ ratio, which has a neutral calculated charge, had almost a neutral in a zeta potential measument (approximately $+2 \mathrm{mV}$ ). A further increase in the amount of pDNA in the lipoplex resulted in net negative zeta potentials.

B16BL6 cells were transfected using lipoplexes prepared with different $\mathrm{P} / \mathrm{L}$ ratios. The transgene efficiency of the lipoplex changed dramatically with a change in $\mathrm{P} / \mathrm{L}$ ratio (Fig. 1C). A lipoplex, at $80 \mathrm{P} / \mathrm{L}$ ratio, showed the highest efficiency, almost same as that of LipofectAMINE, which was used as positive control. At this ratio, the size of the lipoplex was at a maximum, but had almost a neutral charge. The lower lipofection efficiencies of all other lipoplexes were not due to cytotoxicity toward the treated cells, since all the lipoplexes tested showed no detectable cytotoxicity, as evidenced by the trypan blue exclusion test (data not shown).

Effect of P/L Ratio on Lipoplex Size and Transfection Efficiency in the Presence of Serum It is well known that
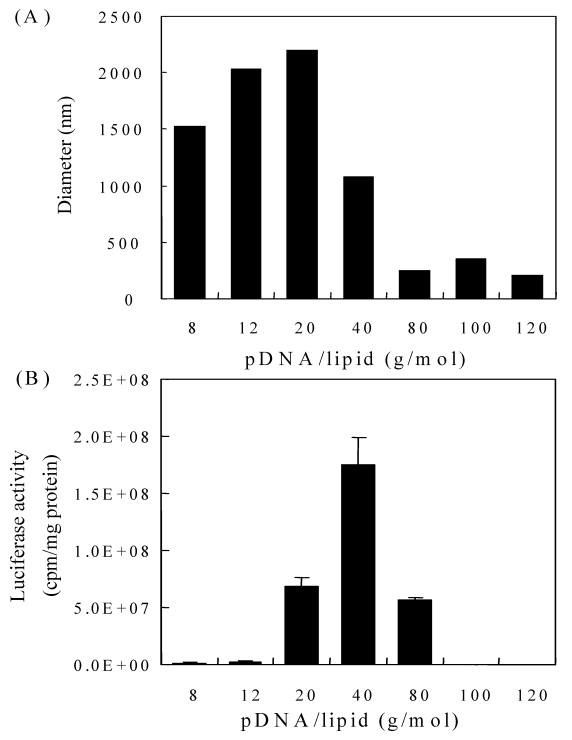

Fig. 2. Effect of $\mathrm{P} / \mathrm{L}$ Ratio on Size and Transfection Efficiency of the Lipoplex in the Presence of Serum

pDNA/TFL-3 complexes (lipoplexes) were prepared, as described in Materials and Methods. The average size (A) of resulting lipoplex were determined after incubation in the presence of $50 \%(\mathrm{v} / \mathrm{v})$ serum for $15 \mathrm{~min}$ at $37^{\circ} \mathrm{C}$. Luciferase activity (B) in B16BL6 cells following lipofection ( $1 \mu \mathrm{g}$ of pDNA) was determined in the presence of $50 \%(\mathrm{v} / \mathrm{v})$ serum according to the method described in the Materials and Methods. Data represent mean \pm S.D. $(n=3)$.

serum has an inhibitory effect on lipofection efficiency. After its systemic administration, the lipoplex immediately encounters serum proteins in the blood stream. Hence, a study in the presence of serum is thought to be very important for the prediction of lipofection efficiency in vivo. Here, the effect of serum was investigated on lipoplex size and lipofection efficiency. For all experiments, the concentration of serum was fixed at $50 \%(\mathrm{v} / \mathrm{v})$ in the incubation medium.

As expected, the presence of serum resulted in a dramatic alteration in lipoplex size compared to the absence of serum (Fig. 2A). The $\mathrm{P} / \mathrm{L}$ ratio needed to give the largest lipoplex size was shifted from 80 to 20 in the presence of serum, compared with the absence of serum. Up to a $\mathrm{P} / \mathrm{L}$ ratio of 40 , the size was increased 6 to 7 -fold, relative to the absence of serum. Increasing the $\mathrm{P} / \mathrm{L}$ ratio to over 40 led to a significant decrease in lipoplex size, 7 to 25 -fold. In the presence of serum, the lipofection efficacy of the lipoplex on B16BL6 cells was also changed dramatically with a change in $\mathrm{P} / \mathrm{L}$ ratio (Fig. $2 \mathrm{~B}$ ) and the $\mathrm{P} / \mathrm{L}$ ratio for the maximum transgene expression was shifted from 80 to $40 \mathrm{P} / \mathrm{L}$. The level of gene expression was relatively lower than those in the absence of serum, except for $\mathrm{P} / \mathrm{L}$ ratios of 20 and 40 (Fig. 2B). At P/L ratios of 20 and 40, transgene expression was increased by approximately 2-fold. LipofectAMINE lost its efficient gene transfer activity in the presence of serum (data not shown). Comparing the changes in lipoplex size and lipofection efficiency, a relationship still partly exists between lipoplex size and lipofection efficiency in the presence of serum.

In Vivo Transfection Study The in vivo efficacy of lipoplex was examined in B16BL6-bearing mice, following an intravenous injection. The assay was carried out $14 \mathrm{~d}$ after the inoculation of B16BL6 cells or an injection of saline. In normal mice, a relatively lower gene expression in all organs including the lungs (Fig. 3, open column) examined were detected at all $\mathrm{P} / \mathrm{L}$ ratios tested (data not shown). Surprisingly, 


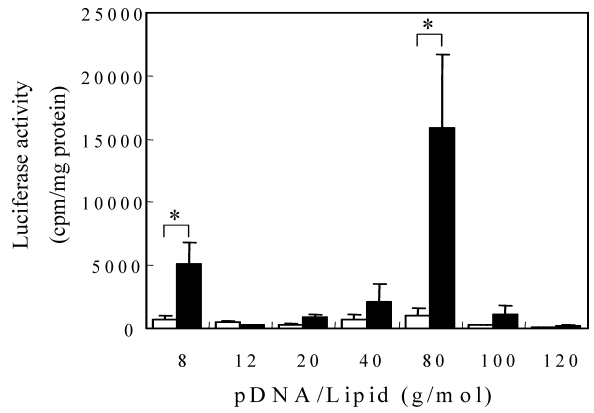

Fig. 3. Effect of $\mathrm{P} / \mathrm{L}$ Ratio of the Lipoplex on Gene Expression in Lungs of Normal and B16BL6 Tumor-Bearing Mice

Lipoplexes, prepared as described in Materials and Methods, were intravenously injected in normal mice or tumor bearing mice at $14 \mathrm{~d}$ post-inoculation of B16BL6 cells. Each mouse received $30 \mu \mathrm{g}$ of pDNA. The lungs of the animals were harvested $24 \mathrm{~h}$ after injection. The luciferase activity in the lungs was determined, as described in Materials and Methods, $24 \mathrm{~h}$ after lipoplex injection. Open column, normal mouse; filled column, tumor-bearing mouse. Data represent the mean \pm S.D. $(n=4)$.

in tumor-bearing mice, a relatively higher gene expression in the lungs was obtained at several $\mathrm{P} / \mathrm{L}$ ratios, whereas gene expression in various another organs was very low or absent (data not shown). The rank order of increased gene expression level was for $\mathrm{P} / \mathrm{L}$ ratios of $80,8,40,100$ and 20 . The tendency observed in tumor-bearing mice reflects the in vitro lipofection results obtained in the absence of serum rather than those in the presence of serum.

To further examine the in vivo transfection efficiency, the lipoplex was intravenously injected into tumor-bearing mice at the indicated days after tumor cell inoculation. Gene expression in the lung was assayed $24 \mathrm{~h}$ after lipoplex injection. Two different lipoplexes with $\mathrm{P} / \mathrm{L}$ ratios of 8 and 80 , which showed relatively higher transgene expression (Fig. 3), were used in this study. The progression of tumor in lung was estimated by counting the number of tumor nodules on the surface of the lung. As shown in Fig. 4A, the extensive progression of tumor was not observed until at $14-15 \mathrm{~d}$ after tumor cell inoculation. For both lipoplexes, while tumor bearing mice showed no significant gene expression at earlier periods (until $7 \mathrm{~d}$ after tumor inoculation), they showed significant gene expression at a later period (over $10 \mathrm{~d}$ after tumor inoculation) (Fig. 4B). With the lipoplex (8 P/L ratio), significant gene expression occurred when the lipoplex was administered at $10 \mathrm{~d}$ after tumor inoculation, then reached a maximum at $14 \mathrm{~d}$ and remained constant even at 17 and $21 \mathrm{~d}$. In the case of the lipoplex ( $80 \mathrm{P} / \mathrm{L}$ ratio), significant gene expression occurred when the lipoplex was given at $10 \mathrm{~d}$ after tumor inoculation, reached a maximum level at $14 \mathrm{~d}$ and then decreased almost to the control level up to $21 \mathrm{~d}$. The level of gene expression by the lipoplex with a $80 \mathrm{P} / \mathrm{L}$ ratio was 2times higher than that for the lipoplex with a $8 \mathrm{P} / \mathrm{L}$ ratio at earlier after tumor inoculation, but this value became 8-times lower later. There was no obvious relation between the gene expression induced by TFL-3 and the number of tumor nodules in the lung.

Fluorescence Microscopic Study of Lung The lipoplex (gWIZ-GFP/ TFL-3) with a P/L ratio of 8 or 80 was intravenously injected into tumor-bearing mice at $14 \mathrm{~d}$ post-tumor inoculation. In the normal lung, GFP expression was observed in endothelial cells of the microvasculature and there was no significant difference in the area of GFP expression with both lipoplexes tested (data not shown). In the tumor-
(A)

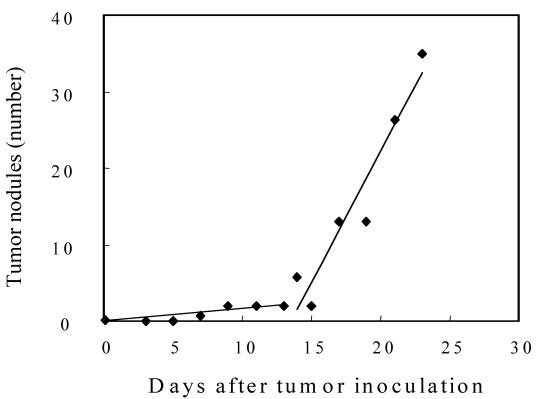

(B)

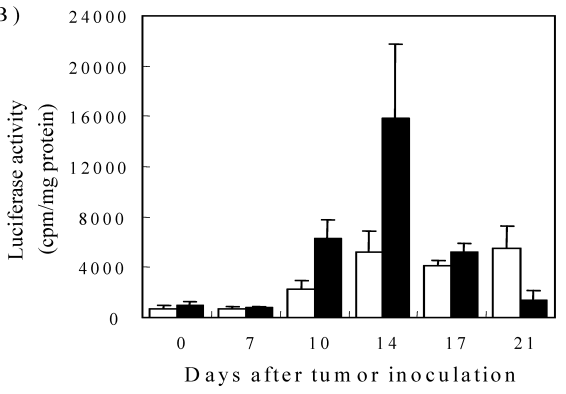

Fig. 4. Relation between Tumor Progression and Gene Expression in Lungs

(A) B16BL6 cells $\left(5 \times 10^{4}\right.$ cells in $0.2 \mathrm{ml}$ PBS) were intravenously injected into a $\mathrm{C} 57 \mathrm{BL} / 6$ mouse. At the indicated day, the mice were sacrificed. The number of tumor nodules on the surface of the lung was counted. (B) At the indicated day post-tumor inoculation, the lipoplex with a $\mathrm{P} / \mathrm{L}$ ratio of 8 or $80(30 \mu \mathrm{g}$ of $\mathrm{pDNA})$ was injected intravenously. The luciferase activity in the lungs was determined as described in Materials and Methods $24 \mathrm{~h}$ after lipoplex injection. Open column, lipoplex of $8 \mathrm{P} / \mathrm{L}$ ratio; filled column, lipoplex of $80 \mathrm{P} / \mathrm{L}$ ratio. Data represent the mean \pm S.D. $(n=4)$.

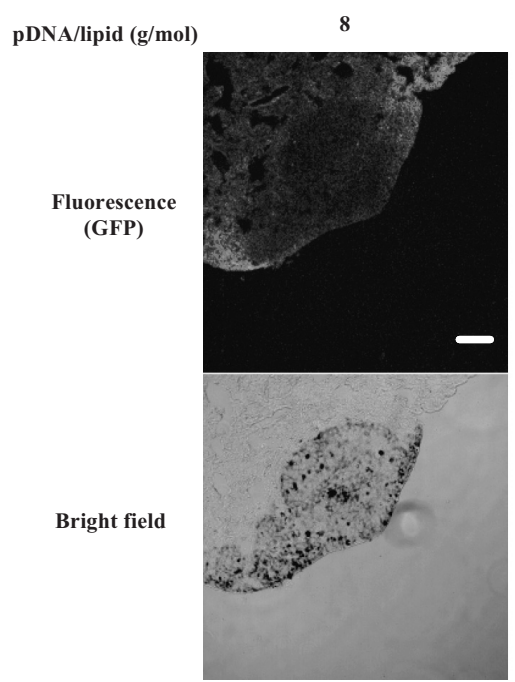

(A)

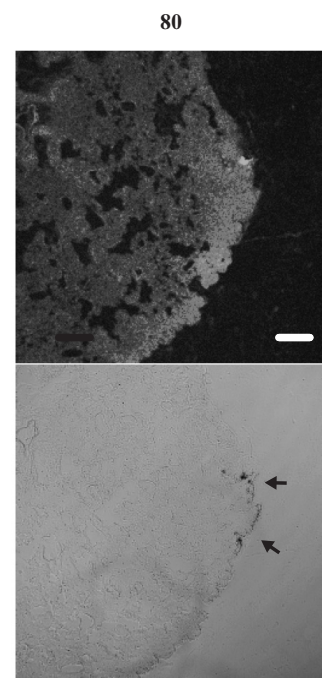

(B)
Fig. 5. Fluorescent Microscopic Observation of Expressed GFP in the Tumor-Bearing Lung

At $14 \mathrm{~d}$ post-tumor inoculation, the lipoplex with a $\mathrm{P} / \mathrm{L}$ ratio of 8 or $80(30 \mu \mathrm{g}$ of pDNA) was injected intravenously. At $24 \mathrm{~h}$ after injection, GFP expression in the lungs was observed under a confocal laser scan microscope as described in Materials and Methods. In the left picture (A), the dark area in the bright field represents tumors in the prepared section. In the right picture (B), the black arrow heads represents very tiny tumors in the prepared section. The scale bar in the pictures represents $100 \mu \mathrm{m}$. The pictures shown are typical examples of multiple evaluations.

bearing lung, with the lipoplex with a $\mathrm{P} / \mathrm{L}$ ratio of 8 , the expressed GFP was barely detected in the tumor area (Fig. 5A). Interestingly, the strongest GFP expression was observed in the tissue around the tumor. In contrast to this observation, with the lipoplex with a $\mathrm{P} / \mathrm{L}$ ratio of 80 , the expressed GFP 
was detected in the entire lung tissue unrelated to the area of tumor growth (Fig. 5B).

\section{DISCUSSION}

Many parameters are known to affect the efficiency of transfection by lipoplex (lipofection) in vitro and in vivo. Among these parameters, one of factors that affect lung lipofection is the interaction of lipoplex with serum. It has been reported that incubation in pure serum or serum-containing media could decrease the extent of lipoplex delivery and alter its intracellular fate ${ }^{19,20)}$ and even cause the lipoplex to disintegrate upon prolonged exposure. ${ }^{18,21)}$ However, an injected lipoplex is rapidly cleared from the circulation ${ }^{18,22)}$ and internalized in the lungs, ${ }^{23}$ ) thus ruling out long-term exposure to serum. In addition, Sakurai et al. showed the pre-incubation of a DOTAP/Chol lipoplex with serum for as long as $30 \mathrm{~min}$ did not significantly impair lipofection in the lungs. ${ }^{24)}$ Accordingly, the importance of the above mentioned serum effects for lung tansgene expression following intravenous injection of lipoplex is still an open question.

Our earlier study showed that the size of lipoplex is a major determinant in the lipofection efficiency of TFL-3 in the presence of serum with A431, a human epidermoid carcinoma cell line, and SBC-3, a human lung cancer cell line. ${ }^{25)}$ Therefore, in this study, we focused on the effect of lipoplex size as the result of from interaction with serum proteins on in vitro lipofection and on their relation with in vivo lipofection in tumor-bearing mice. As shown in Figs. 1 and 2, the importance of lipoplex size was also confirmed in in vitro lipofection with B16BL6 cells in the absence or presence of serum. Interestingly, in the presence of serum, the size of lipoplex that has over $\mathrm{P} / \mathrm{L}$ ratio of 40 was decreased relative to absence of serum (Figs. 1A, 2A). This may result from that the larger lipoplex as a result of aggregation of smaller lipoplexes was dispersed by the interposition of serum proteins. ${ }^{10)}$ The in vitro lipofection of the lipoplex in the presence of serum (Fig. 2) showed no obvious relation with in vivo lipofection in tumor-bearing mice (Fig. 3). Probably, the alteration in the size of lipoplex, resulted from aggregate formulation with anionic serum proteins after intravenous injection, is not a major factor in determining in vivo lipofection efficiency in our system. Otherwise, an interaction with serum proteins would not lead to a predominant change in the size of the lipoplex after an intravenous injection. During the intravenous injection of lipoplex, the lipoplex mixes with about $50-100 \mu \mathrm{l}$ of serum, presuming cardiac flow through the tail vein and abdominal veins to be $c a$. $300 \mu$ lof serum per $3 \mathrm{~s}^{26)}$ In this situation, i.e. $50-100 \mu \mathrm{l}$ serum $/ 200 \mu \mathrm{l}$ of lipoplex dispersion, the serum concentration is much considerably diluted compared with our in vitro experimental conditions $(50 \%(\mathrm{v} / \mathrm{v}))$. In the presumed in vivo condition, at the lipoplex/serum ratio, the cationic membrane surfaces are only partially associated with anionic serum proteins, which therefore may not act as bridges between lipoplexes, thereby not inducing lipoplex aggregation well.

Previous studies using TFL-3 showed a high transfection efficiency in vitro, even in the presence of serum, and in vivo a low toxicity was reported by intraperitoneal injection. ${ }^{9)}$ Accordingly, TFL-3 would be expected to be applicable for in vivo use with systemic injection. Here, we report that tumor- related gene expression in the lung is achieved by using TFL3 (Fig. 3). In our artificial metastasis model of murine melanoma, some micrometastases were established in the lung due to the direct intravenous injection of the cells. Once established, the pulmonary metastases secrete factors that promote angiogenesis and then begin to proliferate progressive, resulting in an enlarged vascular bed and an increase in vascular permeability. Simberg et $a .^{27)}$ recently reported that hypervascularization in the liver induced by VEGF did not increase level of lipofection with a DOTAP/CHOL lipoplex, despite the increased entrapment of lipoplex in the liver. Based on the fact that enlarging the vascular bed and increasing vascular permeability in the liver were not sufficient to promote efficient lipofection, they concluded that the lungs might be an organ that is simply susceptible than liver. Accordingly, the predominant tumor-related gene expression in this study may have been obtained due to the following reasons: (a) the lung is a more lipofectable organ, (b) hypervascularization occurred due to tumor progression, and (c) extensive proliferation of tumor cells occurred. But, we can not exclude influence of alteration of biological conditions related to tumor progression on the resulting gene expression in the lung.

The $\mathrm{P} / \mathrm{L}$ ratio of a lipoplex of TFL-3 affected the degree of gene expression in tumor-bearing lungs (Fig. 3). In addition, pulmonary gene expression was dependent on the time after tumor cell inoculation (Fig. 4). These observations lead to the possibility that the lipoplex causes gene expression in a different part of the lung. This area-specific gene expression may be related, in part, to the pattern of interaction of lipoplexes with tumor cells, pulmonary endothelial cells and normal cells. To assess this, a fluorescent microscopic study was carried out. The findings showed that the lipoplex with a $\mathrm{P} / \mathrm{L}$ ratio of 8 expressed GFP over the surrounding tumor cells, while the lipoplex, with a $\mathrm{P} / \mathrm{L}$ ratio of 80 , expressed it in the entire lung tissue without any specificity (Fig. 5). The first pass entrapment $(60-80 \%$ of the liposomes are entrapped within minutes after intravenous injection) ${ }^{18,22,28)}$ can be attributed to the highly extended lung capillary bed and was proposed to explain the predominant gene expression in the lungs. ${ }^{28,29)}$ Ito et al. ${ }^{30)}$ recently reported that vascular endothelial cells, probably under angiogenesis, in the lungs of tumor bearing mice, which demonstrates an increased uptake of cationic liposome-DNA complexes and transgene expression compared to normal mice. In addition, they showed that the increased uptake of liposome-DNA complexes by tumor cells over normal cells is also responsible for the increased transgene expression. The alveolar macrophages present in a tumor microenvironment could be less responsible for the transgene expression, since it has been reported that macrophages are less phagocytic or are inactivated by factors produced by the tumor cells. ${ }^{31,32)}$ Accordingly, the $\mathrm{P} / \mathrm{L}$ ratios of lipoplexes showing the largest difference in physicochemical properties, as shown in Figs. 1 and 2, affect the microdistribution of lipoplexes, their interaction with various cells and uptake by those cells after intravenous injection, may result in the area-specific gene expression in tumor-bearing lungs.

Although the present study demonstrates that the increased gene expression in tumor-bearing lungs is probably due to an increased uptake of lipoplex by tumor cells and pulmonary 
endothelial cells of normal or angiogenic vessels over the surrounding normal cells, it is possible that other factors such as endosomal release, nuclear uptake, and increased transcription and translation, may play a role in the different degree and distribution pattern observed for gene expression in the lung. A further examination of these individual phenomena may aid in the development of an effective gene delivery vector. However, a note of caution is that the experimental metastases model used in this study, although performed in such a way that the lung metastases are established, has some limitations. It does not mimic the full sequence of events that primary tumors undergo. These cancer cells may undergo additional changes. Thus, it may not be predictive of the responses of these tumors to a systemically delivered gene therapy agent. Therefore, the results of the present study, although relevant for lung cancer therapy, represent only an intermediate step on the path toward the development of a systemic gene transfer with a broad utility.

Acknowledgements We thank Mr. Kenji Irimura, Drug Safety Research Laboratory, Taiho Pharmaceutics, for preparation of histopathological slide of lung. We wish to thank Dr. Hiroshi Kikuchi, Daiichi Pharmaceuticals, for helpful suggestions and Dr. Milton S. Feather for his helpful advice in writing the English manuscript. This study was supported, in part, by research grants from the Japanese Clinical Oncology Fund and the Osaka Cancer Research Foundation.

\section{REFERENCES}

1) Crystal R. G., Science, 270, 404-410 (1995).

2) Edelstein M. L., Abedi M. R., Wixon J., Edelstein R. M., J. Gene Med., 6, 597-602 (2004).

3) Hughes R. M., J. Surg. Oncol., 85, 28-35 (2004).

4) Nathwani A. C., Benjamin R., Nienhuis A. W., Davidoff A. M., Vox Sang., 87, 73-81 (2004).

5) Temin H. M., Hum. Gene Ther, 1, 111-123 (1990).

6) Serikawa T., Suzuki N., Kikuchi H., Tanaka K., Kitagawa T., Biochim. Biophys. Acta, 1467, 419-430 (2000).

7) Nguyen L. T., Ishida T., Ukitsu S., Li W. H., Tachibana R., Kiwada H., Biol. Pharm. Bull., 26, 880-885 (2003).

8) Li W., Ishida T., Tachibana R., Almofti M. R., Wang X., Kiwada H., Int. J. Pharm., 276, 67-74 (2004).

9) Kikuchi A., Aoki Y., Sugaya S., Serikawa T., Takakuwa K., Tanaka K.,
Suzuki N., Kikuchi H., Hum. Gene Ther, 10, 947-955 (1999).

10) Lew D., Parker S. E., Latimer T., Abai A. M., Kuwahara-Rundell A., Doh S. G., Yang Z. Y., Laface D., Gromkowski S. H., Nabel G. J., Hum. Gene Ther, 6, 553-564 (1995).

11) Tranchant I., Thompson B., Nicolazzi C., Mignet N., Scherman D., J. Gene Med., 6 (Suppl. 1), S24-35 (2004).

12) Song Y. K., Liu F., Chu S., Liu D., Hum. Gene Ther., 8, 1585-1594 (1997).

13) Takakura Y., Nishikawa M., Yamashita F., Hashida M., J. Drug Target., 10, 99-104 (2002).

14) Dass C. R., Int. J. Pharm., 267, 1-12 (2003).

15) Templeton N. S., Lasic D. D., Frederik P. M., Strey H. H., Roberts D. D., Pavlakis G. N., Nat. Biotechnol., 15, 647-652 (1997).

16) Ries L. A., Wingo P. A., Miller D. S., Howe H. L., Weir H. K., Rosenberg H. M., Vernon S. W., Cronin K., Edwards B. K., Cancer, 88, 2398-2424 (2000)

17) Parker S. E., Ducharme S., Norman J., Wheeler C. J., Hum. Gene Ther, 8, 393-401 (1997).

18) Niven R., Pearlman R., Wedeking T., Mackeigan J., Noker P., Simpson-Herren L., Smith J. G., J. Pharm. Sci., 87, 1292-1299 (1998).

19) Escriou V., Ciolina C., Lacroix F., Byk G., Scherman D., Wils P., Biochim. Biophys. Acta, 1368, 276-288 (1998).

20) Yang J., Chen S., Huang L., Michalopoulos G. K., Liu Y., Hepatology, 33, 848-859 (2001).

21) Zelphati O., Uyechi L. S., Barron L. G., Szoka F. C., Jr., Biochim. Biophys. Acta, 1390, 119-133 (1998).

22) Mahato R. I., Anwer K., Tagliaferri F., Meaney C., Leonard P., Wadhwa M. S., Logan M., French M., Rolland A., Hum. Gene Ther., 9, 2083-2099 (1998).

23) Barron L. G., Gagne L., Szoka F. C., Jr., Hum. Gene Ther, 10, 16831694 (1999).

24) Sakurai F., Nishioka T., Saito H., Baba T., Okuda A., Matsumoto O., Taga T., Yamashita F., Takakura Y., Hashida M., Gene Ther., 8, 677686 (2001).

25) Almofti M. R., Harashima H., Shinohara Y., Almofti A., Li W., Kiwada H., Mol. Membr. Biol., 20, 35-43 (2003).

26) Davies B., Morris T., Pharm. Res., 10, 1093-1095 (1993).

27) Simberg D., Weisman S., Talmon Y., Faerman A., Shoshani T., Barenholz Y., J. Biol. Chem., 278, 39858-39865 (2003).

28) Li S., Tseng W. C., Stolz D. B., Wu S. P., Watkins S. C., Huang L., Gene Ther., 6, 585-594 (1999).

29) Song Y. K., Liu F., Liu D., Gene Ther, 5, 1531-1537 (1998).

30) Ito I., Began G., Mohiuddin I., Saeki T., Saito Y., Branch C. D., Vaporciyan A., Stephens L. C., Yen N., Roth J. A., Ramesh R., Mol. Ther., 7, 409-418 (2003).

31) Sotomayor E. M., Fu Y. X., Lopez-Cepero M., Herbert L., Jimenez J. J., Albarracin C., Lopez D. M., J. Immunol., 147, 2816-2823 (1991).

32) Lopez D. M., Handel-Fernandez M. E., Cheng X., Charyulu V., Herbert L. M., Dinapoli M. R., Calderon C. L., Anticancer Res., 16 3923-3929 (1996). 